
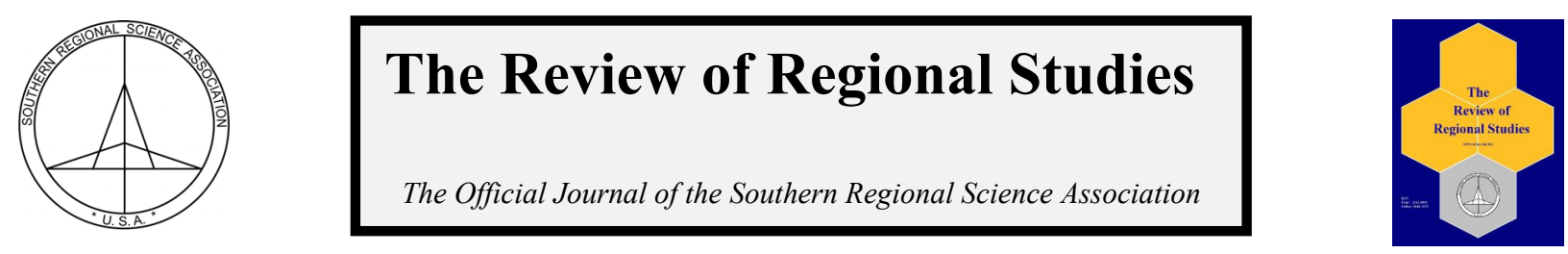

\title{
The Economic Resilience of U.S. Counties during the Great Recession*
}

\author{
Yicheol Han ${ }^{\mathrm{a}}$ and Stephan J. Goetz ${ }^{\mathrm{a}, \mathrm{b}}$ \\ ${ }^{a}$ Northeast Regional Center for Rural Development; National Agricultural and Rural Development Policy Center, \\ Pennsylvania State University \\ ${ }^{b}$ Department of Agricultural Economics, Sociology, and Education, Pennsylvania State University
}

\begin{abstract}
A regional economy perturbed by a shock may move onto a new growth path by reestablishing economic linkages both internally and with other regions. This dynamic property of regions has recently been explained in terms of regional economic resilience. In this paper, we introduce a more refined measure of economic resilience and then apply it to monthly employment data for U.S. counties in the 2007-2009 downturn. We suggest that describing and analyzing the distinct response patterns during this downturn are important starting points for policy makers to understand the spatial resilience of the US economy.
\end{abstract}

Keywords: Regional economic growth, regional economic resilience, Great Recession

JEL Codes: R10, R11, E32

\section{INTRODUCTION}

The terror attacks of September 11, 2001, Hurricane Katrina in 2005, the Great Recession of 2007-2009, and long-term economic decline in the Great Lakes region, among other disturbances, have focused policy makers' attentions on the ability of regional economies not only to continue business operations during such shocks and disasters, but also to recover from them. A shock that occurs within a local area can spread through an entire economy because of the interrelationships that exist between economic agents and regions. In this process, each region responds in unique ways to a shock, reflecting its particular spatial and industrial structures. Levels of economic resilience also vary across regions. Shocks or disturbances can result from disasters, climate change, or an economic crisis more generally.

Regional economic resilience is defined as a region's capacity to absorb and resist shocks as well as to recover from them. Here, a regional economy is defined as a system of interrelated components within a given environment. This perspective seeks to understand a system's response to shocks by modeling the interrelationships between components of both the broader system and of each individual component. Regional economic resilience can be measured by the response to a shock both in the aggregate economy and in the sub-national units (such as states or counties) that make up the aggregate national economy. Existing studies have focused only on the resilience of larger economic units and, more importantly, they do not provide a specially designed quantitative index for measuring resilience.

\footnotetext{
* This work was supported by United States Department of Agriculture, National Institute of Food and Agriculture Grants No. 2012-70002-19385 and 2014-51150-22094. Corresponding Author: Y. Han E-mail: yuh14@psu.edu
}

(C) Southern Regional Science Association 2015. 
In this paper we propose a new method to measure regional economic resilience and apply it to U.S. counties as fundamental components of regional economic systems. We examine regional economic responses to a specific shock by focusing on three variables. The first is the time of impact or peak occurrence of the shock, that is, the point at which the recession began. Recessions begin earlier in some counties than in others, and counties peak at different times and also exit from recessions at different points in time. By looking at when the period of peak employment occurred in each county, we obtain insights into how recessions spread and are experienced over time in different counties. The second variable measures the response of counties to the shock as reflected in employment declines (recession) and subsequent increases (recovery). The last variable measures the relationship between the recession and the recovery to arrive at a novel measure of regional economic resilience.

The following section reviews the existing literature on regional economic resilience and elaborates on our motivation for the study. Subsequent sections explain the measures we use for recession, recovery, and resilience of U.S. counties, before we proceed to the analysis. We conclude by summarizing results and suggesting next steps for regional economic resilience research.

\section{LITERATURE REVIEW}

Although the concept of resilience has only recently been applied to regional development, it has been studied in various fields including ecology, business, engineering and materials science, and psychology (see, e.g., Holling, 1973; Gunderson, 2000). The word "resilience" has roots in the Latin word resilire which means "to recoil or spring back into shape after bending, stretching, or being compressed." (Oxford Dictionary of English, 2010) In the scientific literature, the term was first used in physics and the material sciences to describe the elasticity of materials (Shaikh and Kauppi, 2010). Resilient materials are able to resume their original shape or position after external forces have altered them in some way. When a material is deformed beyond a certain threshold, it loses its elastic property and cannot return to its original shape. Thus, resilience broadly means the capacity of material to resist an impact without being permanently deformed.

A system's unique resistance and recovery patterns depend on the properties of its components and on its overall structure (Albert, Jeong, and Barabási, 2000; Janssen et al., 2006; Saavedra et al., 2011; Scheffer et al., 2012; Basile, de Nardis, and Pappalardo, 2013; Dai, Korolev, and Gore, 2013). Holling (1973) identified two distinct aspects of a system's response to a shock: resilience and stability. He defines a system's resilience, as its ability "to absorb changes of state variables, driving variables, and parameters, and still persist" (p. 17). In this definition, resilience is an inherent characteristic of a system, and change is the result of a disturbance. Stability implies a system's ability "to return to an equilibrium state after a temporary disturbance" (p. 17). Here, the velocity of the return to the equilibrium state is a key characteristic of stability; the faster a system recovers, the more stable it is. A given system can be resilient yet unstable, and vice versa. Yet, in many studies, "resilience" has come to represent a synthesis of the concepts of both resilience and stability. It usually refers to a system's overall robustness, and the rapidity and flexibility with which it recovers from an external shock. For example, Tobin (1999, p. 13) defined resilience as the capacity to "minimize the effects of disasters and at the same time have the ability to recover quickly." Alberti et al. (2003, p. 1170)

(C) Southern Regional Science Association 2015. 
also defined resilience as the capacity to "tolerate alteration before reorganizing around a new set of structures and processes."

Economic resilience on a regional level has been defined as the ability of a region "to anticipate, prepare for, respond to, and recover from a disturbance" (Foster, 2007, p. 14) or "to recover successfully from shocks to its economy that either throw it off its growth path or have the potential to [do so]" (Hill, Wial, and Wolman, 2008, p. 2). In applying these definitions, we face three questions: (1) what is the most suitable quantitative measure of regional economic resilience, (2) what is the most suitable geographic unit, and (3) how can we calculate a growth path or equilibrium in an economic system after a shock?

Two approaches are commonly used to measure regional economic resilience. One examines regional properties or characteristics that reflect economic resilience. Examples include macroeconomic stability, microeconomic market efficiency, governance, and social development (Briguglio et al., 2006); the degree to which resources are owned locally, the organizational capacity of residents, and the local capacity of institutions to adapt and reorganize in response to a shock (Matarrita-Cascante and Trejos, 2013); local knowledge network structure (Crespo, Suire, and Vicente, 2014); and income equality, economic diversification, regional affordability, and business environment (Augustine et al., 2013). Using these variables as predictors requires an accounting for the weighted contribution of each variable to a region's resilience. To date, no common method for weighting the different variables has been agreed upon.

The other approach to measuring regional economic resilience analyzes changes to a region's representative measure in response to a shock. Davies (2011) studied regional resilience by examining the correlations between unemployment and gross domestic product (GDP), population, share of manufacturing, construction, finance, and public infrastructure investment. Martin (2012) used the structural composition of employment change across nine industries, and Fingleton, Garretsen, and Martin (2012) added regional employment change rates during recessionary and recovery periods in the U.K.

In the search for a suitable unit of measure for regional economic resilience, prior studies have focused on large economic units such as countries (Briguglio et al., 2006; Davies, 2011), regions $^{1}$ (Fingleton, Garretsen, and Martin, 2012; Martin, 2012), metro areas (Augustine et al., 2013), and large cities (Clark, 2009; Simmie and Martin, 2010). In some large and especially across noncontiguous geographical units, however, it is difficult, if not impossible, to examine the spread of the shock in the regional system and, more generally, to analyze regional economic resilience from a systems perspective. Even if most counties experience economic recession, some local areas may grow even during a downturn and exhibit different economic patterns.

In the recovery phase, a system reorganizes its structure to cope with the disturbance and returns to the pre-shock growth path or equilibrium state. In particular, during a recession a regional economy may experience firm bankruptcies, salary reductions, and unemployment: job losses also mean that family income drops, poverty rises, and health insurance coverage may be lost. The region may see a subsequent brain drain and loss of human capital. However, lower costs and relocated workforces also provide opportunities to create new economic activities in the region during a recovery. Therefore, even though the system may return to pre-shock levels,

\footnotetext{
${ }^{1}$ The regions in both of these studies were defined as Greater London, South East, Eastern, South West, East Midlands, West Midlands, Yorks-Humberside, North West, North East, Wales, Scotland, and Northern Ireland in the U.K..
}

(C) Southern Regional Science Association 2015. 
the recovered economic system will likely not be the same as the previous system because its structure can change during the reorganization. Hence, growth paths and equilibrium states of economic systems are interchangeable, and they adapt in response to shocks. Following this reorganization notion of economic systems, Martin (2012 p.10) defined resilience as "the capacity of a regional economy to reconfigure, that is adapt, its structure (firms, industries, technologies and institutions) so as to maintain an acceptable growth path in output, employment and wealth over time."

Adaptive resilience (Martin, 2012), socio-ecological resilience (Folke et al., 2010), or the evolutionary perspective (Simmie and Martin, 2010) interpret the notion of reorganization that is derived from the theory of complex adaptive systems. In a complex adaptive system, the components seem to "learn" and to evolve based on the experience within the system itself. Examples of such systems, wherein one observes adaptations that reflect "learning," are socioeconomic systems and ecosystems. According to the complex adaptive systems perspective, the pre-existing growth path or equilibrium state may no longer exist after a shock or disruption and, instead, an alternative growth path may emerge (Christopherson, Michie, and Tyler, 2010). In such a case, "past behavior of the system is no longer a reliable predictor of future behavior even when circumstances are similar" (Duit et al., 2010, p.367). Thus, regional economic resilience need not imply a return to a previous path or equilibrium state after a shock; instead, the system may evolve in an entirely new direction. The important question then is how fully and how quickly the system bounces back from the disturbance.

\section{METHODS}

An economic system's responses to a shock can be divided into two stages: the "absorption" of the changes experienced while the shock persists and its "rebound" from the shock during the recovery. We focus specifically on the ability of a region to "absorb" and "rebound" in defining our measure of economic resilience. Given that we are looking at a recession as a shock, we consider the amount of decline relative to the expected employment, ${ }^{2}$ and the amount of recovery relative to the lowest post-shock employment (see Figure 1).

Expected employment is the region's employment based on the long-run growth path in the absence of a shock. We calculate this path for each region using a compound growth rate. Assume that a shock occurs at time $t_{1}$ and that the region's actual employment at time $t_{0}$ and $t_{1}\left(t_{0}\right.$ $\left.<t_{1}\right)$ is $y_{t 0}$ and $y_{t 1}$, respectively. Then the compound growth rate, $r$, for this period is calculated as:

(1) $r=\left(y_{t_{1}} / y_{t_{0}}\right)^{1 / t_{1}-t_{0}}-1$

Using the compound growth rate, we compute the expected employment $\hat{y}_{t}$ at time $t\left(t>t_{1}\right)$ as:

(2) $\hat{y}_{t}=y_{t_{1}}(1+r)^{t-t_{1}}$

\footnotetext{
${ }^{2}$ As an alternative to employment we could have used a measure of output or labor compensation, but this would introduce potential problems with adjusting for inflation over time across spatial units. In addition, monthly data on output are not available.
}

(C) Southern Regional Science Association 2015. 


\section{Figure 1: Regional Economic Change from a Major Shock and Concepts of drop and rebound}

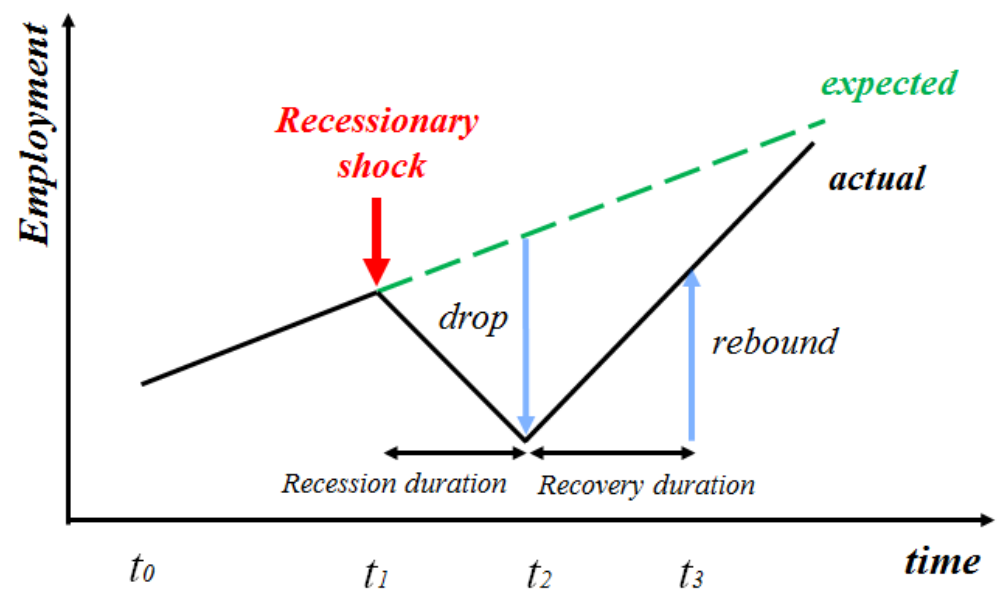

The ability to "absorb" refers to a region withstanding change or resisting the negative effects of a shock. We measure this ability as an impulse - by how much a region's employment drops below the expected employment after a shock - and refer to this as a drop (Fig. 1). Even though two regions may have the same employment reduction, the region with the higher growth rate will suffer a larger economic shock. We designate $y_{t 2}$ as the region's lowest post-shock employment occurring at time $t_{2}\left(t_{1}<t_{2}\right)$ and expected employment at time $t_{2}$ as $\hat{y}_{t 2}$. Then the drop is calculated as the deviation of the actual employment $y_{t 2}$ from the expected employment $\hat{y}_{t 2}$ at time $t_{2}$, as:

(3) Drop $=\frac{\hat{y}_{t_{2}}-y_{t_{2}}}{\hat{y}_{t_{2}}}$

A region not affected by shock maintains its long-run growth pattern. In such a case, actual and expected employment are identical $\left(y_{t 2}=\hat{y}_{t 2}\right)$, and the drop is 0 . In the most extreme case, where a region experiences a large decline and has no employment at $t_{2}\left(y_{t 2}=0\right)$, the $d r o p$ has a maximum value of 1 (measured in absolute terms).

A shock forces a regional economic system to reorganize itself and may produce a stronger post-shock economic structure. Thus, the pre-shock long-run or steady state growth path is replaced with a new path during the recovery process and we refer to a region bouncing back from a shock and reorganizing as a rebound. The rebound represents the velocity of recovery from recession and is calculated as the rate of change between recovered employment, $y_{t} 3$, and the lowest employment, $y_{t 2}\left(t_{3}>t_{2}\right)$, as:

(4) Rebound $=\frac{y_{t_{3}}-y_{t_{2}}}{y_{t_{2}}} \cdot \frac{1}{t_{3}-t_{2}}$

When a region fails to escape from the trough, its employment has not changed by time $t_{3}$ $\left(y_{t 3}=y_{t 2}\right)$, and the rebound value is 0 . The rebound reflects the elasticity of a region's economic activities or its velocity of bounce-back after being adversely shocked. A region might enjoy a high rebound if it produces goods and services required to recover from an economic recession, 
if it has sound financial policy and discretionary expenditures and inventories, or if it implements tax cuts to counteract negative effects of the shock.

Resilient systems are able to minimize the effect of a shock while obtaining the largest possible benefit from reorganization. A more robust structure experiences a smaller drop while a more elastic structure allows for a greater rebound. We define regional economic resilience as the standard score of logarithm of ratio of rebound and drop as:

$$
\text { (5) } \text { Resilience }=\frac{\text { ratio }- \text { ave }(\text { ratio })}{\text { stdev }(\text { ratio })}, \quad \text { ratio }=\ln \left(\frac{\text { Rebound }-\min (\text { Rebound })+s}{\text { Drop }-\min (\text { Drop })+s}\right)
$$

where ave() represents an average, and $\operatorname{stdev()}$ is the standard deviation. To ensure that the ratio of drop and rebound is a positive number, which allows us to use the logarithmic function, we add two variables: $\min ()$ and $s$. The $\min ()$ is the smallest value among all regions' values and $s$ indicates a small number. In this study we use 0.0001 as the value for $s$. A region that experiences a smaller drop and greater rebound against the same-scaled shock is more resilient.

We treat a county as a regional unit of the U.S. economic system. To measure the resilience of U.S. counties, we use monthly employment in each of the 3,138 U.S. counties, ${ }^{3}$ as provided by U.S. Department of Labor Bureau of Labor Statistics, ${ }^{4}$ limiting this study's focus to the period leading up to and following the Great Recession, as described and delineated below. Following the U.S. Census Bureau, we use the X-12 ARIMA to adjust for seasonal effects in the monthly employment data.

Figure 2: Total employment in the United States, 2000-2014

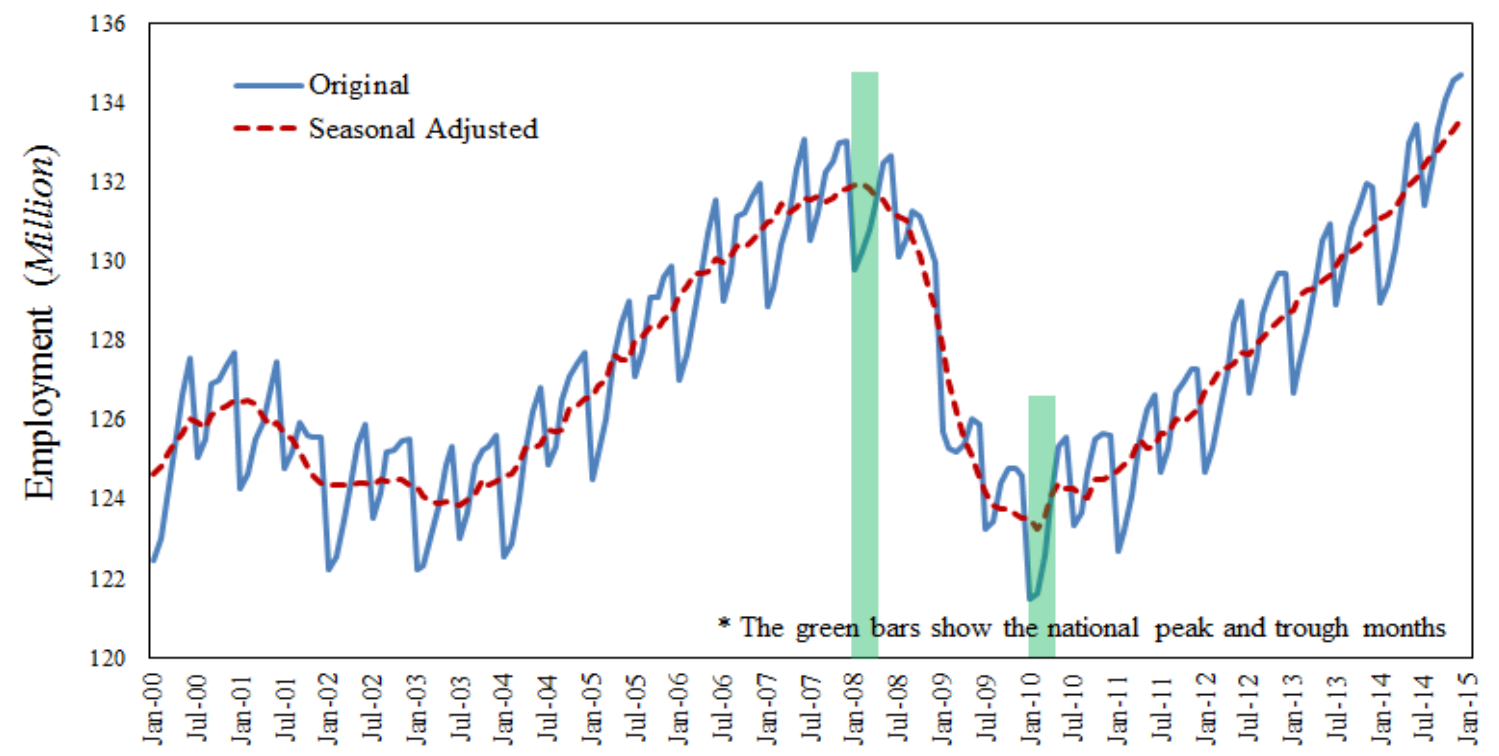

Time

\footnotetext{
${ }^{3}$ Out of the 3,141 counties and county-equivalents in the 2014 BLS employment data, we merged four counties into two counties each which were split in 2007 (Skagway-Hoonah-Angoon Census Area, Alaska) and in 2008 (Wrangell-Petersburg Census Area, Alaska), and exclude one county that has missing employment data (Greenlee County, Arizona). As a result, we use the remaining 3,138 counties in our analysis.

${ }^{4}$ Available online in October 2015 at http://www.bls.gov/cew/datatoc.htm
}

(C) Southern Regional Science Association 2015. 
In an economic cycle, a local maximum (peak) indicates the end of an expansion and the beginning of a recession. Thus, an economic downturn starts in the month after a county records peak employment. Nationally, employment in the last decade peaked in February 2008, and the recession lasted 24 months (see Figure 2), but the economic cycles of each county start and end at different times and vary in duration. To allow for flexibility while imposing some consistency, we limit the candidate month when a peak may occur to the period February 2006-Feburary 2010, which is the national peak month (February 2008) \pm 2 years. Our rationale for doing this is that a peak occurring before February 2006 could belong to another economic cycle, while a peak after February 2010 could indicate a peak in the next economic cycle. We estimate the long-run development path for each county as the compound growth rate over the three years (36 months) before the peak employment month ( $t_{0}=t_{1}-36$ in Figure 1). A local minimum (bottom or trough), in contrast, signals the end of the county's recession and the beginning of its recovery (expansion). We identify a county's minimum employment after its peak and designate that as a trough. This leaves us with county-level employment data for 2003-2014 to measure the drop, rebound, and resilience.

\section{RESULTS}

\subsection{Employment Changes}

Individual counties show a variety of patterns of peak employment; most counties recorded peak employment in February 2008 (4.5 percent) and August 2008 (4.0 percent). Considering the entire year, 30.9 percent of counties peaked in 2006, 27.3 percent in 2007, 32.2 percent in 2008, 7.5 percent in 2009, and 2.0 percent in 2010. Figure 3 shows that the last downturn started in Michigan, South Florida, and the suburban counties of large cities such as New York, San Francisco, Atlanta, Charlotte, Seattle, and Las Vegas, most of which had overheated housing markets. The recession subsequently spread into smaller counties located in the central U.S.

A trough signals the end of a recession and the beginning of an expansion. Most counties experienced trough employment in February 2010 (7.0 percent) and January 2010 (4.7 percent). Considering entire years, one in four counties recorded trough employment in 2010 (27.8 percent) and 2009 (27.2 percent). Of the remaining counties, 0.2 percent experienced their trough in 2006 ; 0.7 percent in 2007; 1.8 percent in 2008; 15.4 percent in $2011 ; 10.0$ percent in 2012; 11.7 percent in 2013; and 5.3 percent in 2014. After a trough, each county enters a recovery process. To estimate the amount of recovery over a consistent period (of the same duration), we use six months after the trough to measure recovered employment $\left(t_{3}=t_{2}+6\right.$ in Figure 1$)$.

The gap between a county's peak and trough months shows the recession's local duration (see Figure 1). Because the U.S. recorded its national peak employment in February 2008 and the trough in February 2010, most counties are expected to have had two years of recession duration. But the distribution of recession duration across counties varies significantly. Taking the national peak as a benchmark, counties with an earlier peak experienced longer-lasting recession durations, while later-peaking counties had shorter recession durations. The average recession duration of 2006 peak-year counties was 4.6 years, compared with 3.5 years for those peaking in 2007, 2.5 years in 2008, 2.0 years in 2009, and 1.8 years in 2010 (see Figure 4). Based on the peak month and the recession duration in Figure 4, we calculate that the trough month of most counties occurred in August 2010 (trough $=$ peak + recession duration). Earlier-peaking counties did not recover until 2010.

(C) Southern Regional Science Association 2015. 
Figure 3: Map of the Peak Year of Downturn in U.S. Counties during the Great Recession

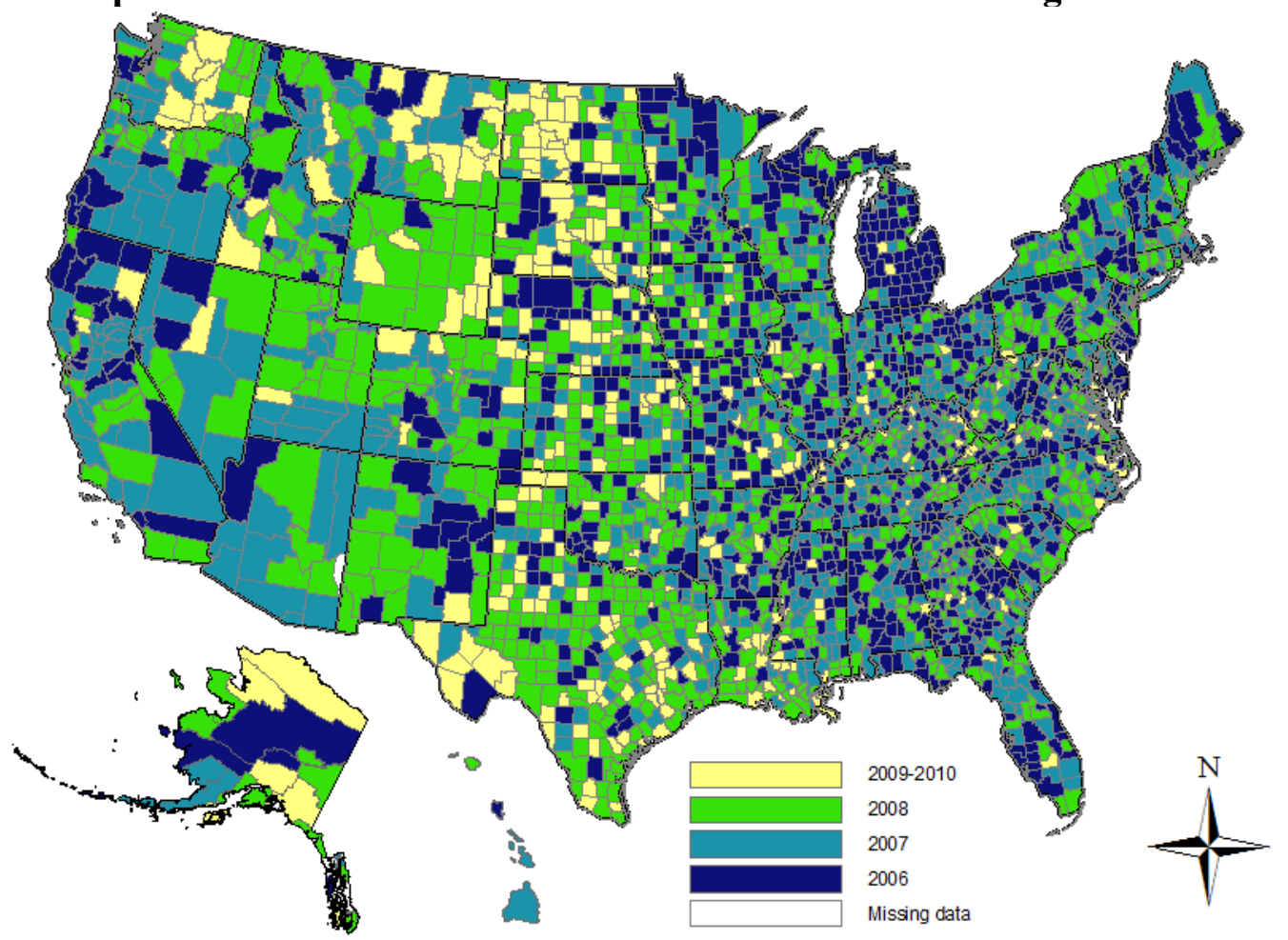

Drop and rebound are measured using employment in the peak and trough months of each county, respectively. Employment in some counties either rose continuously (12 counties) or did not recover before July 2014 (290 counties), ${ }^{5}$ meaning that these counties did not experience a local maximum or minimum during the period examined in our study (2006-2014). We cannot measure the rebound of counties whose trough month occurred after July 2014 because we define the rebound as the employment increase during six months following the trough. We exclude these 302 counties from the resilience analysis, and use the remaining 2,836 (90.4 percent) counties to measure resilience. About 8.5 percent of counties (268 counties) experienced a double-dip; that is, they fell into a recession again after a short recovery. A double-dip county has multiple local maxima and minima. To keep our analysis manageable we simplified these cases of double-dip recessions by focusing instead on the global maxima and minima in the given period.

\subsection{Economic Drop and Rebound}

The drop measures the amount of impulse that a county experiences from a shock. A smaller drop means that a county had stronger resistance or more economic stability in the face of the same-scale shock. The distribution of the drop variable is positively skewed with mode 0.12 , median 0.16 , and mean 0.19 (see Figure $5 \mathrm{~b}$ ). This means that a few counties experienced a significant employment decrease, compared to the U.S. average. The largest drop was 0.90, in Loving County, Texas, and 0.88 in Trimble County, Kentucky, while the smallest was -0.33 in

\footnotetext{
${ }^{5}$ From 2006 to 2014, 20 counties recorded peaks in February 2006 and troughs after July 2014; these counties experienced a continuous decline in employment during the entire period. The 270 counties that recorded a July 2014 or later trough after their peak did not enter into a recovery process after the shock.
}

(C) Southern Regional Science Association 2015. 


\section{Figure 4: Peak Month of Counties and Their Average Recession Duration}

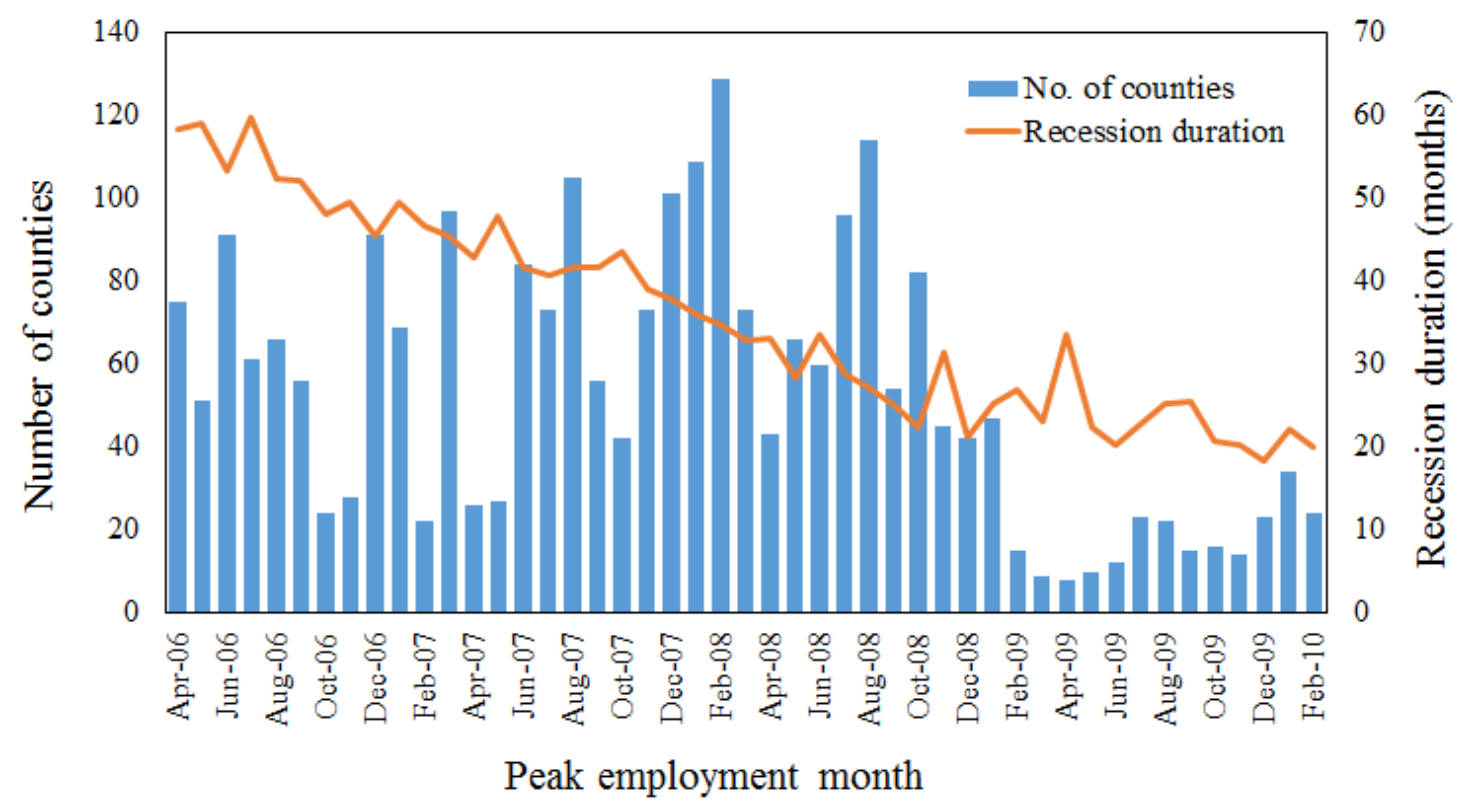

Houston County, Texas and -0.23 in Lawrence County, Tennessee. A negative drop means that the actual employment in the trough month was larger than the expected employment: 30 of 2,836 counties (1.1 percent) recorded a negative drop. These counties experienced an economic decline before the 2007 downturn; all have a negative compound growth rate, with an average of -0.003 , compared with a national average of 0.002 . The economic decline in these counties likely originated from other economic events unrelated to the 2007 downturn.

The counties with large drops share several common characteristics. First, they enjoyed high economic growth before the shock. Figure 5a shows that the drop is proportional to the compound growth rate with a correlation coefficient of 0.635 : counties with high economic growth lost momentum because of the shock, and then entered into a deep recessionary period. Next, counties adjacent to metro areas exhibited a higher drop than non-adjacent counties (Table 1). To estimate the adjacency to metro areas, we use Rural-Urban Continuum Codes (RUCC) (Parker, 2013). The 2007 downturn is known to have originated, in large part, from subprime mortgages and homeowners who lost their jobs and could not pay back their mortgages, which affected the financial industry before spreading to other industries. The financial industry is concentrated in large metropolitan areas, and economic activities in metro-adjacent counties generally depend more heavily on metro areas than do counties not adjacent to metropolitan areas. Thus, adjacent counties demonstrate more significant negative effects from metro areas and recorded higher drops than did non-adjacent counties. Lastly, large-drop counties are geographically clustered (see Figure 6 and Table 1). Based on the U.S. Bureau of Economic Analysis Regions, ${ }^{6}$ the Southeast, Southwest, Rocky Mountain, and Far West regions experienced a large drop while New England and Mideast recorded a small drop.

\footnotetext{
${ }^{6}$ For a map of these regions, which are composed of states, see https://united-states.reaproject.org/img/maps/BEA_Regions Full.png.
}

(C) Southern Regional Science Association 2015. 
Figure 5: Relationship between drop and rebound:

Dispersion of drop and rebound According to

(a) the Compound Growth Rate and the Distributions of (b) drop and (c) rebound.
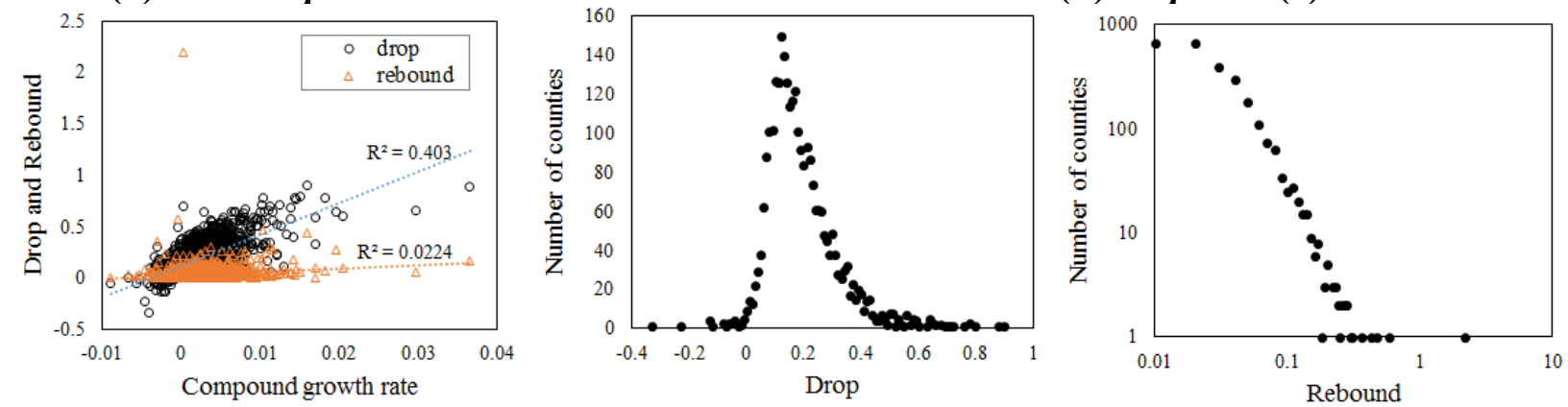

Figure 6: Map of drop of U.S. Counties in the Great Recession

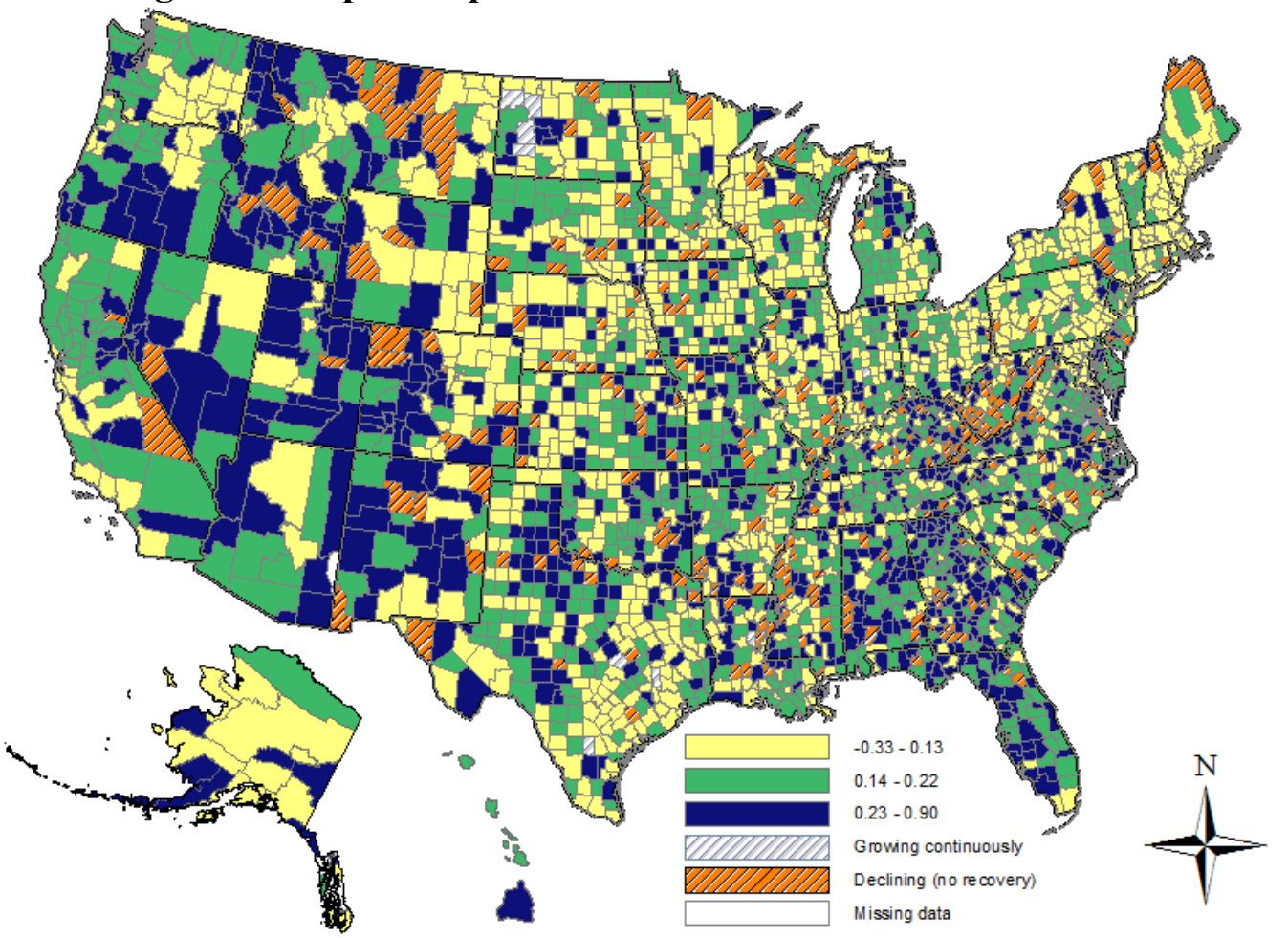

As noted, the rebound reflects the recovery velocity after the recession. A large rebound means that a county recovered quickly. The average rebound of U.S. counties was 0.035 , which means, on average, employment increased by 3.5 percent in the half year following the trough. However, counties experienced highly uneven recoveries: the distribution of rebound exhibits a power-law decay (Fig. 5c). Thus most counties recovered only a small portion of their employment after the recession, while a few grew rapidly. In order words, a few counties with high rebound either received a large proportion of the federal resources that aided economic recovery, responded particularly well to local policies and/or to federal assistance programs, or were inherently less vulnerable to the shock emanating from the housing sector. 
Table 1: Statistics for drop Data by Rural-Urban Continuum Codes and BEA Regions

\begin{tabular}{|c|c|c|c|c|c|}
\hline Category definition & obs. & avg. & stdev. & $\min$. & $\max$. \\
\hline U.S. average & 2,836 & 0.188 & 0.117 & -0.329 & 0.902 \\
\hline \multicolumn{6}{|l|}{ Rural urban continuum codes (RUCC) } \\
\hline 1 Counties in metro areas of 1 million population or more & 412 & 0.164 & 0.099 & -0.059 & 0.883 \\
\hline 2 Counties in metro areas of 250,000 to 1 million population & 354 & 0.170 & 0.100 & -0.008 & 0.663 \\
\hline 3 Counties in metro areas of fewer than 250,000 population & 329 & 0.179 & 0.119 & -0.061 & 0.782 \\
\hline 4 Urban population of 20,000 or more, adjacent to a metro area & 198 & 0.163 & 0.081 & -0.131 & 0.395 \\
\hline 5 Urban population of 20,000 or more, not adjacent to a metro area & 86 & 0.153 & 0.078 & 0.023 & 0.501 \\
\hline 6 Urban population of 2,500 to 19,999 , adjacent to a metro area & 527 & 0.194 & 0.107 & -0.229 & 0.644 \\
\hline 7 Urban population of 2,500 to 19,999 , not adjacent to a metro area & 379 & 0.176 & 0.111 & -0.329 & 0.711 \\
\hline 8 Completely rural or less than 2,500 urban population, adjacent to a metro area & 192 & 0.241 & 0.148 & -0.005 & 0.783 \\
\hline 9 Completely rural or less than 2,500 urban population, not adjacent to a metro area & 359 & 0.238 & 0.149 & -0.040 & 0.902 \\
\hline \multicolumn{6}{|l|}{ BEA regions } \\
\hline 1 New England & 63 & 0.111 & 0.066 & 0.038 & 0.511 \\
\hline 2 Mideast & 166 & 0.125 & 0.081 & -0.008 & 0.661 \\
\hline 3 Great Lakes & 404 & 0.158 & 0.086 & -0.131 & 0.558 \\
\hline 4 Plains & 561 & 0.171 & 0.109 & -0.068 & 0.776 \\
\hline 5 Southeast & 920 & 0.214 & 0.119 & -0.229 & 0.883 \\
\hline 6 Southwest & 352 & 0.192 & 0.129 & -0.329 & 0.902 \\
\hline 7 Rocky Mountain & 193 & 0.242 & 0.147 & 0.001 & 0.782 \\
\hline 8 Far West & 177 & 0.199 & 0.117 & 0.026 & 0.783 \\
\hline
\end{tabular}

Source: Authors' calculations 
The largest rebound scores were as follows: 2.20 in Mercer County, Missouri, and 0.58 in Alpine County, California ; the smallest were 0.00 in Gloucester County, New Jersey, and 0.00 in Palm Beach County, Florida. The two largest rebound counties are rural with small populations (RUCC 9 and 8), while the lowest two rebound counties are in metro areas (RUCC 1). On average, counties in metro areas (RUCC 1-3) recorded a small rebound (less than the U.S. average) and non-metro counties with small populations enjoyed comparatively fast economic recoveries. Interestingly, growth rates and adjacency to a metro area do not affect the recovery: the correlation coefficient between rebound and compound growth rate is 0.16 (see Figure 5a) and average rebound values of counties in adjacent to metro areas and not adjacent counties are not different (see Table 2). The counties in the Plains, Southeast, Southwest, Rocky Mountain, and Far West regions had a large rebound, while the counties in New England, the Mideast, and Great Lakes regions showed a small rebound (see Table 2 and Figure 7).

\subsection{Economic Resilience}

Resilience measures the ability of a county to resist a shock and to recover quickly. A county with a smaller drop and larger rebound has greater resilience. The county with the largest resilience was Houston County, Texas (9.68). This county recorded a drop of -0.33 and a rebound of 0.035 . The county with the third-largest resilience was Lawrence County, Tennessee, (3.23) with a -0.23 drop and 0.089 rebound. In both cases, these counties had a negative compound growth rate, so we assume that they experienced an economic shock even before the

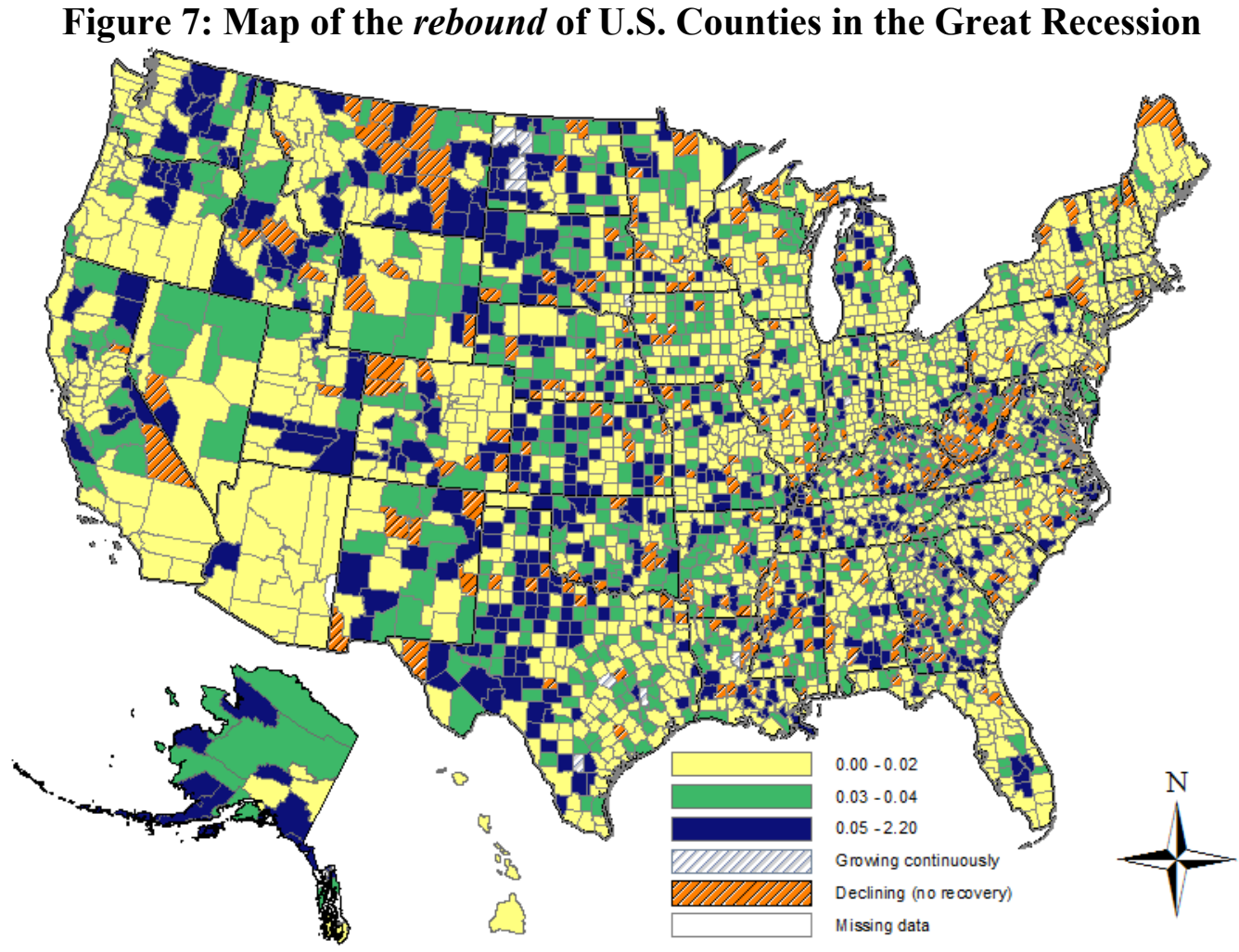

(C) Southern Regional Science Association 2015. 
Table 2: Statistics for rebound data by Rural-Urban Continuum codes and BEA regions

\begin{tabular}{|c|c|c|c|c|c|}
\hline definition & obs. & avg. & stdev. & $\min$. & $\max$. \\
\hline U.S. average & 2,836 & 0.035 & 0.055 & 0.000 & 2.199 \\
\hline \multicolumn{6}{|l|}{ Rural urban continuum codes (RUCC) } \\
\hline 1 Counties in metro areas of 1 million population or more & 412 & 0.021 & 0.020 & 0.000 & 0.167 \\
\hline 2 Counties in metro areas of 250,000 to 1 million population & 354 & 0.023 & 0.029 & 0.000 & 0.303 \\
\hline 3 Counties in metro areas of fewer than 250,000 population & 329 & 0.029 & 0.032 & 0.001 & 0.358 \\
\hline 4 Urban population of 20,000 or more, adjacent to a metro area & 198 & 0.022 & 0.017 & 0.000 & 0.124 \\
\hline 5 Urban population of 20,000 or more, not adjacent to a metro area & 86 & 0.022 & 0.016 & 0.001 & 0.068 \\
\hline 6 Urban population of 2,500 to 19,999 , adjacent to a metro area & 527 & 0.034 & 0.032 & 0.000 & 0.266 \\
\hline 7 Urban population of 2,500 to 19,999 , not adjacent to a metro area & 379 & 0.035 & 0.028 & 0.001 & 0.199 \\
\hline 8 Completely rural or less than 2,500 urban population, adjacent to a metro area & 192 & 0.062 & 0.068 & 0.001 & 0.580 \\
\hline 9 Completely rural or less than 2,500 urban population, not adjacent to a metro area & 359 & 0.066 & 0.124 & 0.000 & 2.199 \\
\hline \multicolumn{6}{|l|}{ BEA regions } \\
\hline 1 New England & 63 & 0.017 & 0.011 & 0.002 & 0.057 \\
\hline 2 Mideast & 166 & 0.019 & 0.022 & 0.000 & 0.223 \\
\hline 3 Great Lakes & 404 & 0.027 & 0.026 & 0.000 & 0.219 \\
\hline 4 Plains & 561 & 0.040 & 0.097 & 0.000 & 2.199 \\
\hline 5 Southeast & 920 & 0.036 & 0.037 & 0.000 & 0.358 \\
\hline 6 Southwest & 352 & 0.039 & 0.041 & 0.001 & 0.433 \\
\hline 7 Rocky Mountain & 193 & 0.041 & 0.044 & 0.002 & 0.282 \\
\hline 8 Far West & 177 & 0.041 & 0.065 & 0.001 & 0.580 \\
\hline
\end{tabular}

Source: Authors' calculation 
Great Recession and were not affected by the Great Recession as such, but still benefited from federal assistance (ARRA). The county with the smallest resilience was Clinton County, Iowa $(-5.22)$; it had a drop of 0.20 and a rebound of 0.00 . The second-smallest resilience was Gloucester County, New Jersey, (-4.95) with a 0.23 drop and 0.00 rebound. $^{7}$

Resilience patterns vary with county population and geographic location (see Table 3). Counties in metro or non-metro areas with large populations (RUCC 1-5) have small resilience: they recorded a smaller drop and rebound than the U.S. average. This means that they have a greater ability to resist external shocks but less capacity to recover. Smaller-population counties in non-metro areas are more resilient (RUCC 6-9); those counties have the largest drop and rebound. Because a small population implies a relatively simple economic structure, policymakers may be better able to choose levers for assuring recovery. The Plains and Southwest regions have great resilience; the Plains region recorded smaller drop and larger rebound scores than the U.S. average, while the Southwest region experienced a larger drop and rebound than the U.S. average. The low resilience of New England and the Mideast is due to a small rebound (smaller drop and rebound than the U.S. average), while that of the Far West is due to a large drop (larger drop and smaller rebound). Figure 8 shows the geography of U.S. resilience as determined by our measure. Many counties in the Great Plains States, where agriculture dominates, show up as resilient. States such as Pennsylvania, Wisconsin and North Carolina tend to have many counties with low resilience or that declined throughout. Georgia has many counties in the middle resilience range, while next door Alabama has more counties with low resilience. Other than this, there are no strong patterns especially in the center of the nation in terms of resilience.

Figure 8: Map of resilience of U.S. counties in the Great Recession

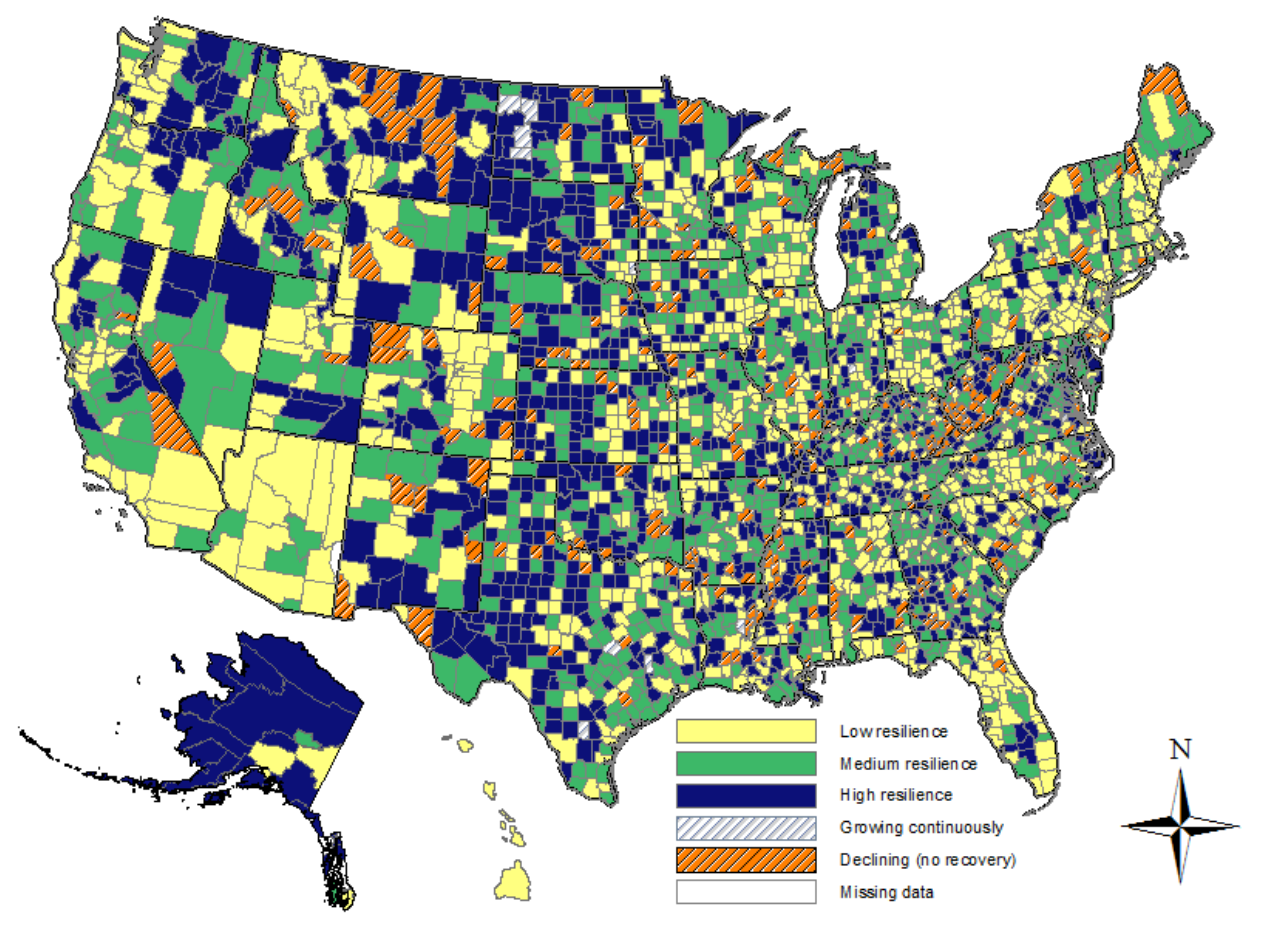

${ }^{7}$ Local economic resilience data compiled for this study are available at: http://aese.psu.edu/nercrd/community/economic-
resilience

(C) Southern Regional Science Association 2015. 
Table 3: Statistics for resilience data by Rural-Urban Continuum codes and BEA regions

\begin{tabular}{|c|c|c|c|c|c|}
\hline definition & obs. & avg. & stdev. & $\min$. & $\max$. \\
\hline U.S. average & 2,836 & 0.000 & 1.000 & -5.215 & 9.680 \\
\hline \multicolumn{6}{|l|}{ Rural urban continuum codes (RUCC) } \\
\hline 1 Counties in metro areas of 1 million population or more & 412 & -0.395 & 0.914 & -4.953 & 1.812 \\
\hline 2 Counties in metro areas of 250,000 to 1 million population & 354 & -0.380 & 0.928 & -3.949 & 2.481 \\
\hline 3 Counties in metro areas of fewer than 250,000 population & 329 & -0.135 & 0.930 & -3.545 & 2.726 \\
\hline 4 Urban population of 20,000 or more, adjacent to a metro area & 198 & -0.325 & 0.944 & -5.215 & 1.556 \\
\hline 5 Urban population of 20,000 or more, not adjacent to a metro area & 86 & -0.309 & 0.933 & -3.209 & 1.227 \\
\hline 6 Urban population of 2,500 to 19,999 , adjacent to a metro area & 527 & 0.047 & 0.944 & -4.045 & 3.226 \\
\hline 7 Urban population of 2,500 to 19,999 , not adjacent to a metro area & 379 & 0.201 & 0.984 & -3.715 & 9.680 \\
\hline 8 Completely rural or less than 2,500 urban population, adjacent to a metro area & 192 & 0.565 & 0.916 & -2.797 & 2.970 \\
\hline 9 Completely rural or less than 2,500 urban population, not adjacent to a metro area & 359 & 0.646 & 0.889 & -4.471 & 4.175 \\
\hline \multicolumn{6}{|l|}{ BEA regions } \\
\hline 1 New England & 63 & -0.414 & 0.726 & -2.493 & 1.048 \\
\hline 2 Mideast & 166 & -0.476 & 1.030 & -4.953 & 1.948 \\
\hline 3 Great Lakes & 404 & -0.120 & 0.873 & -3.839 & 2.090 \\
\hline 4 Plains & 561 & 0.172 & 0.934 & -5.215 & 4.175 \\
\hline 5 Southeast & 920 & -0.011 & 1.012 & -4.471 & 3.226 \\
\hline 6 Southwest & 352 & 0.221 & 1.037 & -4.045 & 9.680 \\
\hline 7 Rocky Mountain & 193 & 0.011 & 1.031 & -2.770 & 2.000 \\
\hline 8 Far West & 177 & -0.044 & 1.115 & -3.230 & 2.970 \\
\hline
\end{tabular}

Source: Authors' calculations

C Southern Regional Science Association 2015. 
Counties are unique in terms of their populations, distances to metro areas, economic structures, and geographical regions. Therefore, and as we have shown, each county exhibits unique action and reaction patterns for its recession and recovery processes. Examining the causes and consequences of these various patterns in future research would be fruitful for establishing a better understanding of these novel patterns of economic geography. Furthermore, this understanding could potentially yield insights and lessons for preventing future downturns.

\section{CONCLUSION}

A regional economy perturbed by a shock may establish a new growth path; this represents the "action and reaction" of an economic system. Here, we proposed a new regional economic resilience measure and analyzed the economic resilience of U.S. counties in the Great Recession. The dataset consisted of monthly employment for 3,138 U.S. counties between 2003 and 2014, and we were able to include a total of 2,836 counties in our calculations.

We use employment as the representative measure of economic activity of a county. Employment is a function of economic changes occurring during recessions and recoveries. In a recession, employees may lose their high-income jobs and be forced into low-paying ones. Even if total employment in a county remains fixed, changes in the economic structure and pay available may lead to an economic decline in the county. On the other hand, aggregate employment change does not capture industry advances from low-technology industries to hightechnology ones (and related rises in income) during the recovery process, if such advances occur. Basically, total employment shows only how many individuals work in a county and not what kind of jobs they have. We submit that personal income data can show these more nuanced, qualitative changes. Further studies are needed to analyze and compare the employment and income changes for regional economic resilience in a more detailed fashion.

As we have noted, one common point of emphasis in the definition of regional economic resilience is that a regional economy is a system - a set of components and the given environment. Therefore, a deeper understanding of each component and the contextual environment is important for understanding regional economies and their resilience. In this study, we do not consider the effect of counties' individual internal properties on regional economic resilience. However, an exploration of the determinants of resilience based on the internal properties of individual counties would be an interesting next step. A rich set of future studies can examine the effects of various independent variables such as income, population density, land area, population age, educational attainment, social capital stocks, industrial structure, etc., on the measure of resilience presented here as a dependent variable.

As a component of an economic system, a county has direct or potential relationships with other counties. This study focuses on the economic interaction between counties based only on their rural/urban statuses and examines "relationship" as adjacency to a metro area, based on RUCC. Counties adjacent to metro areas did experience more serious shocks than non-adjacent counties. However, this variable is limited in its ability to explain the relationships between counties in a complex economic system, and we would need spatial statistical tools or a more sophisticated dataset to account for and present these relationships more precisely. If two counties are highly related to each other, or if their economies are integrated, they may indeed share large portions of labor, market, goods and services, etc. We suggest that commuting, 
migration, and transportation between counties can represent county relationships more explicitly.

One possible method for measuring these relationships is to examine the economic complexity of counties (Arthur 1999; Hidalgo et al., 2007; Martin and Sunley, 2007; Eagle, Macy, and Claxton, 2010). Economic complexity does not simply refer to the number or scale of interactions in a county, but includes the synergistic effects from the interactions within it. For example, an economy's complexity in the economic input-output table reflects the various goods and services produced and the synergistic effects among industries within a region. Briguglio et al. (2009) argued that the internal balance between demand and supply interactions within a region is an important determinant of regional economic resilience. A county with a more complex economic structure could disperse the negative impact from a shock while enjoying high economic resilience.

To investigate counties' environments, we used regional dummies (BEA regions). Social and economic factors influence a county's resilience, e.g., similar response patterns are found in the New England-Mideast and in Southeast-Southwest regions. This raises the question of what the appropriate geographic aggregate unit or region is for this kind of analysis. One possible alternative would be to account for the community structure of regional economic systems. A "community" is broadly defined as a system consisting of components that interact more strongly and intensely than others within the system (Wasserman and Faust, 1994; Watts and Strogatz, 1998). Closely connected counties share economic characteristics and therefore likely exhibit similar response patterns to external shocks. Thus, the community structure of a regional economy should provide a new perspective to understand the aggregate economic response and resilience. In turn, these insights could help to develop unique and specific policies for different regions to improve their stability, resilience, and growth prospects over time.

\section{REFERENCES}

Albert, Réka, Hawoong Jeong, and Albert-László Barabási. (2000) "Error and Attack Tolerance of Complex Networks," Nature, 406, 378-382.

Alberti, Marina, John M. Marzluff, Eric Shulenberger, Gordon Bradley, Clare Ryan, and Craig Zumbrunnen. (2003) "Integrating Humans into Ecology: Opportunities and Challenges for Studying Urban Ecosystems," Bioscience, 53, 1169-1179.

Arthur, W. Brian. (1999) “Complexity and the Economy,” Science, 284, 107-109.

Augustine, Nancy, Hal Wolman, Howard Wial, and Mara McMillen. (2013) "Regional Economic Capacity, Economic Shocks, and Economic Resilience." MacArthur Foundation Research Network Working Paper: Washington, DC.

Basile, Roberto, Sergio de Nardis, and Carmine Pappalardo. (2013) "Firm Heterogeneity and Regional Business Cycles Differentials," Journal of Economic Geography, 14, 10871115.

Briguglio, Lino, Gordon Cordina, Stephanie Bugeja, and Nadia Farrugia. (2006) "Conceptualizing and Measuring Economic Resilience." University of Malta Economics Department Working Paper. 
Briguglio, Lino, Gordon Cordina, Nadia Farrugia, and Stephanie Vella. (2009) "Economic Vulnerability and Resilience: Concepts and Measurements," Oxford Development Studies, 37, 229-247.

Christopherson, Susan, Jonathan Michie, and Peter Tyler. (2010) "Regional Resilience: Theoretical and Empirical Perspectives," Cambridge Journal of Regions, Economy and Society, 3, 3-10.

Clark, Greg. (2009) Recession, Recovery and Reinvestment: The Role of Local Economic Leadership in a Global Crisis. OECD Publishing: Paris.

Crespo, Joan, Raphael Suire, and Jerome Vicente. (2014) "Lock-in or Lock-out? How Structural Properties of Knowledge Networks Affect Regional Resilience," Journal of Economic Geography, 14, 199-219.

Dai, Lei, Kirill S. Korolev, and Jeff Gore. (2013) "Slower Recovery in Space Before Collapse of Connected Populations," Nature, 496, 355-358.

Davies, Sara. (2011) "Regional Resilience in the 2008-2010 Downturn: Comparative Evidence from European Countries," Cambridge Journal of Regions, Economy and Society, 4, 369382.

Duit, Andreas, Victor Galaza, Katarina Eckerberg, and Jonas Ebbesson. (2010) "Governance, Complexity, and Resilience," Global Environmental Change, 20, 363-368.

Eagle, Nathan, Michael Macy, and Rob Claxton. (2010) "Network Diversity and Economic Development," Science, 328, 1029-1031.

Fingleton, Bernard, Harry Garretsen, and Ron Martin. (2012) "Recessionary Shocks and Regional Employment: Evidence on the Resilience of U.K. Regions," Journal of Regional Science, 52, 109-133.

Folke, Carl, Stephen R. Carpenter, Brain Walker, Marten Scheffer, Tetty Chapin, and Johan Rockström. (2010) "Resilience Thinking: Integrating Resilience, Adaptability and Transformability," Ecology and Society, 15, 20-28.

Foster, Kathryn A. (2007) "A Case Study Approach to Understanding Regional Resilience." Institution of Urban and Regional Development Working Paper 2007-08: Berkeley, CA.

Gunderson, Lance. (2000) "Ecological Resilience-In Theory and Application," Annual Review of Ecology and Systematics, 31, 425-439.

Hidalgo, Cesar. A., Bailey Klinger, Albert-László Barabási, and Ricardo Hausmann. (2007) “The Product Space Conditions the Development of Nations," Science, 317, 482-487.

Holling, Crawford S. (1973) "Resilience and Stability of Ecological Systems," Annual Review of Ecology and Systematics, 4, 1-23.

Hill, Edward W., Howard Wial, and Harold Wolman. (2008) "Exploring Regional Economic Resilience," Institution of Urban and Regional Development Working Paper 2008-04: Berkeley, CA.

Janssen, Marco A., Örjan Bodin, John M. Anderies, Thomas Elmqvist, Henrik Ernstson, Ryan R.J. McAllister, Per Olsson, and Paul Ryan. (2006) "Toward a Network Perspective of the Study of Resilience in Social-Ecological Systems," Ecology and Society, 11, 15.

(C) Southern Regional Science Association 2015. 
Martin, Ron. (2012) "Regional Economic Resilience, Hysteresis and Recessionary Shocks," Journal of Economic Geography, 12, 1-32.

Martin, Ron and Peter Sunley. (2007) "Complexity Thinking and Evolutionary Economic Geography," Journal of Economic Geography, 7, 573-601.

Matarrita-Cascante, David and Bernardo Trejos. (2013) "Community Resilience in ResourceDependent Communities: A Comparative Case Study," Environment and Planning A, 45, 1387-1402.

Oxford Dictionary of English, $3^{\text {rd }}$ ed. (2010) Oxford: Oxford University Press.

Parker, Timothy. (2013) Measuring Rurality: Rural-Urban Continuum Codes. U.S. Department of Agriculture, Economic Research Service: Washington, D.C. Available online in October 2015 at http://webarchives.cdlib.org/sw1wp9v27r/http:/ers.usda.gov/Briefing/Rurality/ RuralUrbCon/.

Saavedra, Serguei, Daniel B. Stouffer, Brian Uzzi, and Jordi Bascompte. (2011) "Strong Contributors to Network Persistence Are the Most Vulnerable to Extinction," Nature, 478, 233-236.

Scheffer, Marten, Stephen R. Carpenter, Timothy M. Lenton, Jordi Bascompte, William Brock, Vasilis Dakos, Johan van de Koppel, Ingrid A. van de Leemput, Simon A. Levin, Egbert H. van Nes, Mercedes Pascual, and John Vandermeer. (2012) “Anticipating Critical Transitions," Science, 338, 344-348.

Shaikh, Arshi and Carol Kauppi. (2010) "Deconstructing Resilience: Myriad Conceptualizations and Interpretations," International Journal of Arts and Sciences, 3, 155-176.

Simmie, James and Ron Martin. (2010) "The Economic Resilience of Regions: Towards an Evolutionary Approach," Cambridge Journal of Regions, Economy and Society, 3, 27-43.

Tobin, Graham A. (1999) "Sustainability and Community Resilience: The Holy Grail of Hazards Planning?" Environmental Hazards, 1, 13-25.

Wasserman, Stanley and Katherine Faust. (1994) Social Networks Analysis: Methods and Applications. Cambridge University Press: New York, NY.

Watts, Duncan J. and Steven H. Strogatz. (1998) "Collective Dynamics of 'Small-world' Networks," Nature, 393, 440-442. 